Thorax (1971), 26, 712.

\title{
Diagnosing emphysema from the lung scan
}

\author{
VALERIE Y. M U IR ${ }^{1}$ \\ Clinical Physiology Department, North Middlesex Hospital
}

\begin{abstract}
Lung scan appearances thought to be characteristic of emphysema are described. Three criteria are stated and 44 scans showing all these criteria were selected from 154 lung scans done during a 10-month period: in fact the scans of all the patients (seen in the Clinical Physiology Department during the 10 months) who were thought on clinical grounds to have emphysema had been selected. Three scans were of patients with fibrosing alveolitis with no evidence of airways obstruction and they were easily identified from the chest radiograph. In six patients the diagnosis of emphysema is reasonable but unproved. Three patients show no real evidence of emphysema. Firstly, all the 154 lung scans were done using technetium-99m as the source of $\gamma$-radiation, whereas most authors have used iodine-131 ; secondly, the scanner setting was the same for all the scans, with a minimum $\gamma$-radiation intensity of 30,000 counts $/ \mathrm{min}$ being necessary to produce an adequate scan. The results of this investigation suggest that there is a scan appearance characteristic of emphysema as long as the patient shows other evidence of airways obstruction.
\end{abstract}

It is generally accepted that the perfusion of emphysematous areas of lung is reduced (Reid, 1967) and that lung scanning is an established and safe procedure. Routine reporting of lung scans revealed that patients who were thought on clinical grounds to have emphysema could be identified from defects on the lung scan, which appeared to show a characteristic pattern. As the diagnosis of emphysema can be difficult or impossible if the disorder is not far advanced or if other lung pathology is present, it was decided to investigate whether the scan could be used in such pathology as an aid in diagnosis.

\section{MATERIAL AND METHODS}

All the patients had been referred to the Clinical Physiology Department of the North Middlesex Hospital for evaluation of pulmonary function and clinical reappraisal. In this department all patients suspected of having lung pathology have a lung scan done as a routine.

The investigation was planned in February 1970 to be both retrospective and prospective. All lung scans done during the 10-month period 1 July 1969 to 31 May 1970 would be reviewed. Initially, the scan reports were written after considering clinical information and the chest film, but since February the scan reports have been written on scan appearances alone, to reduce bias. However, as many patients were obviously dyspnoeic or barrel-chested, only rarely was it possible to give a truly unbiased report.

1Present address: Pathology Department, Barnet General Hospital, Barnet, Herts
The 44 patients in this series were selected on scan appearances alone from 154 lung scans done during the 10 months. Subsequent review of all the scan request forms and, when necessary, correlation with hospital notes showed that the scans of all patients $\overrightarrow{\vec{O}}$ suspected on clinical grounds of having emphysema had been selected as showing the characteristic scan.

The diagnosis of chronic generalized pulmonary emphysema with obstruction was made according to Fletcher, Hugh-Jones, McNicol, and Pride (1963). It is generally accepted that some degree of generalized emphysema may be present without any abnorthe criteria in Table $I$ and is in accordance with mality of the chest radiograph.

\section{T A B L E I}

CRITERIA FOR DIAGNOSIS OF CHRONIC GENERALIZED PULMONARY EMPHYSEMA WITH OBSTRUCTION

1. History

2. Clinical findings

3. Radiological appearances

4. Lung function tests, for evidence of irreversible airways obstruc- $N$ tion and air trapping:
(a) VC
(b) $\frac{\mathrm{FEV}_{1} \%}{\mathrm{VC}}$
(c) Peak flow
(d) TLC
(e) $\frac{\text { RV } \%}{\mathrm{TLC}}$
(f) $\mathrm{CO}$ diffusion

Constant dot colour scans were used exclusively. The photoscans did not provide enough contrast or detail for the scans of emphysematous patients to be identified. The scans were done on a Picker Magnascanner III with a $3 \times 2$ inch NaI crystal. The stan- $\mathbb{D}$ dard 19-hole focussing collimator was used throughout. 
Patients were injected with $1 \mathrm{mCi}$ of ${ }^{99 m}$ Tc-labelled macro-aggregated serum albumin, prepared by a modification of Gwyther and Field's (1966) method. The particles were 50 to $100 \mu$ in diameter. The isotope was injected into an antecubital vein, with the patient supine, as flat as possible. Anterior and posterior scans were done routinely. Count rates of 30,000 to 60,000 counts $/ \mathrm{min}$ were obtained and a scanning speed of $120 \mathrm{~cm} / \mathrm{min}$ was used with a time constant of $0.1 \mathrm{sec}$. It was found to be impractical to attempt a scan if the maximum count rate was less than 30,000 counts $/ \mathrm{min}$, if adequately detailed information were to be obtained. If the patient needed more than two pillows, it was not possible to obtain a complete scan, even on the anterior view, because of the mechanical configuration of the scanner.

\section{RESULTS}

The normal lung scan has been well defined by Sasahara, Belko, and Simpson (1968). On the colour scan, areas of high perfusion are red, with orange, yellow, green, blue, violet, and black indicating decreasing levels of perfusion.

The characteristic scan in emphysema (Table II) shows gross, irregular, and diffuse perfusion defects affecting all, or nearly all, of both lungs. The defects are apparently unrelated to the normal lung anatomy, patches of little or no perfusion (blue, violet) merging on to areas of high perfusion (red, orange) in a haphazard and frequently bizarre manner. The 'stippled' appearance of the scans, as specified in Table II, appears as a haphazard distribution of the red, orange, and yellow dots, most characteristically as one or two red dots interspersed with larger numbers of orange and yellow dots and occasionally with green. The areas of 'stippling' vary but are most commonly only a few square centimetres. The 'stippled' appearance becomes less obvious, or disappears, if the time constant of the scanner is increased-when it will not be possible to identify the scans of emphysema.

\section{T A B L E II}

CRITERIA FOR IDENTIFYING EMPHYSEMA ON THE

1. Evidence of widespread lung disorder

2. Gross, irregular, and diffuse perfusion defects

3. A few areas showing 'stippling' of red, orange, or yellow dots

Where bullae were visible on the chest radiograph, there were corresponding defects on the scan but exactly similar defects were seen when there were no corresponding lesions on the film. In some patients the emphysematous process is so far advanced in one lung as to reduce the perfusion in that lung to a very low level-appearing as a large blue or mauve area. A bizarre appearance was seen in one patient, where the perfusion was severely reduced in the mid-zone of each lung. In many patients the upper or lower zones were affected predominantly.

The 44 patients in this series are all those whose scan exhibited all three criteria. The original clinical diagnosis in these patients is shown in Table III. The three patients known to have fibrosing alveolitis were easily identified from the chest radiograph; none of them had any evidence of airways obstruction.

T A B L E I I I

ORIGINAL CLINICAL DIAGNOSIS FOR THE 44 SELECTED SCANS

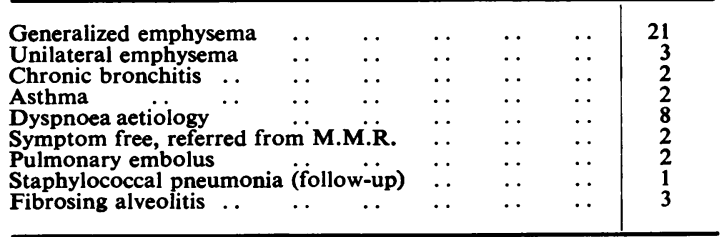

Thus there were 41 patients in whom the diagnosis of emphysema had to be proved. ${ }^{1}$ Six patients had no evidence of emphysema on the chest film.

Three patients have died and have had the diagnosis of emphysema confirmed at necropsy. Twenty patients fulfil all the criteria in Table I. Four patients had severe and disabling emphysema and were too ill to complete the lung function tests. Apart from the evidence of the total lung capacity (TLC) and residual volume (RV)/TLC ratio, they fulfilled all correct criteria. Five patients had no evidence of emphysema on the chest radiograph but fulfilled all other criteria in Table III. Therefore in 32 of the 41 patients the diagnosis of emphysema may reasonably be regarded as proved.

Three patients would not attend for the final lung function tests. Apart from this, they fulfilled all the criteria in Table I, but as their symptoms were not seriously disabling the diagnosis of emphysema must remain reasonable but unproved.

Two patients were symptom free and had been referred by the mass miniature radiography unit on account of bullae on the chest film. One patient shows no evidence of emphysema on criteria 3 and 4 of Table I. In these patients the diagnosis of emphysema is presumptive only.

The results of the lung function tests in three patients do not support conclusively a diagnosis of emphysema. However, it is known (Reid, 1967)

1Full details of lung function tests of these 41 patients are available on request from the author. 
that up to $20 \%$ of both lungs may show macroscopic emphysema when the RV/TLC ratio is 30 $40 \%$. As all these patients had other evidence of emphysema (criteria 1, 2, and 3 of Table I), the diagnosis of emphysema may be considered, again, as reasonable but unproved.

\section{DISCUSSION}

Abnormalities of the lung scan in patients with emphysema were first described by Lopez-Majano, Tow and Wagner (1966). They described scan defects corresponding to bullous lesions on the chest radiograph and they also noticed that defects appeared on the scan when there were no corresponding lesions on the film. They described the defects as being 'irregular, assymetrical and widespread'. These characteristics are now generally accepted (Samad et al., 1968 ; Beerel et al., 1969 ; Cordasco et al., 1968) and are specifically mentioned by Bryant et al. (1968), Poulose, Reba, and Wagner (1968), and Welch et al. (1969). Poulose et al. noted that in the majority $(77 \%)$ of their scans of emphysema, the abnormality could be described as 'diffuse', but concluded that this appearance was not characteristic of emphysema. They also stated that 'complete involvement of an entire lung field was rare'. Walker and Jackson (1969) described the scans as being of larger area than is normal, with activity across the mediastinum. Many of the scans in this series showed this, but it was not a constant feature.

In all the above publications, ${ }^{131} \mathrm{I}$ was used as the source of $\gamma$-radiation in the vast majority of the scans, ${ }^{99} \mathrm{~m}$ Tc being used in a few. The shorter half-life of ${ }^{99 \mathrm{~m} T c}$ ( 6 hours) compared with that of ${ }^{131}$ I (8 days) allows the use of a much larger dose of ${ }^{99} \mathrm{~m} \mathrm{Tc}$. This produces a higher $\gamma$-radiation intensity $(30,000-60,000$ counts $/ \mathrm{min}$ compared with $10,000-20,000$ counts/min when ${ }^{131} I$ is used) and hence the possibility of a more detailed scan (McCready, 1967). Identification of the scan of emphysema is very much dependent upon the scan being adequately detailed.

Early in the course of this investigation it was noticed that maximum detail was produced by using a time constant of $0 \cdot 1 \mathrm{sec}$ and a scanning speed of $120 \mathrm{~cm} / \mathrm{min}$ with the count rates normally obtained. This differs considerably from the recommended setting of the scanner and using it this way renders ${ }^{131} I$ useless as the source of $\gamma$ radiation, if the emphysematous patient is to be identified, unless a larger $\mathrm{NaI}$ crystal is used with a more sophisticated scanner. If the scanner is incorrectly set or if the count rate is less than
30,000 counts $/ \mathrm{min}$, the resulting scan will not be detailed enough for the scan of emphysema to be identified. The unorthodox setting of the scanner and use of ${ }^{99} \mathrm{~m} \mathrm{Tc}$ exclusively may explain why previous authors have not found a scan appear. ance characteristic of emphysema.

The identification of patients with emphysema from the lung scan appearance (with brief reference to the chest radiograph) is at variance with the published work. Only three patients show no real evidence of emphysema. The 44 scans selected included: (1) all patients seen during the 10 months who were thought on clinical grounds to have emphysema; (2) all patients referred from M.M.R. on account of bullae on the chest radio. graph; (3) an additional 15 patients in whom emphysema was not suspected or was suggested only in the differential diagnosis of their symp. toms and in all but one of whom the diagnosis was subsequently proved; (4) only three patients with fibrosing alveolitis and no patient with other pathology. This surely provides strong evidence for the reliability of the criteria in Table II as a means of identifying the scan of emphysema.

I wish to thank Dr. E. N. O'Brien, consultant chest physician and clinical physiologist, for giving so much of his time to help with this project; Mr. R. Wilks and Mr. R. Wighton, physicists, for practical help and for use of the Isotope Laboratory; Mrs. J. Chanides for practical help; Miss J. Dunford, Mrs. J. Taylor, and Mrs. M. Williams for doing the lung function tests ; my husband, Dr. I. S. Muir, for helpful criticism; and Dr. J. J. Segall for much helpful advice.

The work was made possible by a grant from the North-East Metropolitan Regional Hospital Board.

\section{REFERENCES}

Beerel, F. R., Vance, J. W., Cordasco, E. M., Wende, R. W.. 을 and Toffolo, R. R. (1969). Angiograms, laminagrams I and lung scans in emphysema. Arch. intern. Med. 124,8

Bryant, L. R., Cohn, J. E., O’Neill, R. P., Danielsom, G. K., N and Greenlaw, R. H. (1968). Pulmonary blood flow distribution in chronic obstructive airway disease. Amer. Rev. resp. Dis., 97, 832.

Cordasco, E. M., Beerel, F. R., Vance, J. W., Wende, R. W., and Toffolo, R. R. (1968). New aspects of the pulmonary vasculature in chronic lung disease. A comparative study. Angiology, 19, 399.

Fletcher, C. M., Hugh-Jones, P., McNicol, M. W., and Pride, N. B. (1963). The diagnosis of pulmonary emphysema in the presence of chronic bronchitis. Quart. J. Med., 32, 33.

Gwyther, M. M., and Field, E. O. (1966). Aggregated $\mathbb{D}$ Tc99m-labelled albumin for lung scintiscanning. Int. J. appl. Radiat. Isotopes, 17, 485. 
Lopez-Majano, V., Tow, D. E., and Wagner, H. N. (1966). Regional distribution of pulmonary arterial blood flow in emphysema. J. Amer. med. Ass., 197, 81.

McCready, V. R. (1967). Clinical radioisotope scanning. Brit. J. Radiol., 40, 401.

Poulose, K., Reba, R. C., and Wagner, H. N. (1968). Characterization of the shape and location of perfusion defects in certain pulmonary diseases. New Engl. J. Med., 279, 1020.

Reid, L. (1967). The Pathology of Emphysema. Lloyd-Luke, London.
Samad, I. A., Wood, D., Sanders, D. E., Suero, J. T., and Woolf, C. R. (1968). A comparison of pulmonary angiography and intravenous radioactive albumin lung scanning in chronic obstructive pulmonary emphysema. Dis. Chest, 53, 571.

Sasahara, A. A., Belko, J. S., and Simpson, R. G. (1968). Multiple-view lung scanning. J. nucl. Med., 9, 187.

Walker, R. H. Secker, and Jackson, J. A. (1969). Scanning of the lung. Proc. roy. Soc. Med., 62, 799.

Welch, M. H., Richardson, R. H., Whitcomb, W. H., Hammarsten, J. F., and Guenter, C. A. (1969). The lung scan in a1-antitrypsin deficiency. J. nucl. Med., 10,687 . 